\title{
Stereotypical Inferences as Mediators of Age Discrimination: The Role of Competence and Warmth
}

\author{
Franciska Krings, Sabine Sczesny ${ }^{1}$ and Annette Kluge ${ }^{2}$ \\ University of Lausanne, Faculty of Business and Economics, Department of Organizational Behavior, Internef \\ Building, Office 613, 1015 Lausanne, Switzerland, ${ }^{1}$ University of Bern, Faculty of Department of Psychology, \\ Muesmattstrasse 35, 3000 Bern 9, Switzerland, and ${ }^{2}$ University of Duisburg-Essen, Faculty of Engineering, \\ Department of Economic Psychology, Campus Duisburg, Forsthausweg 2, 47048 Duisburg, Germany \\ Corresponding author email: franciska.krings@unil.ch
}

\begin{abstract}
Drawing on theories of stereotype content and role congruity, this research investigated the role of stereotypes for employment discrimination against older candidates. Study 1 investigated the content of stereotypes about older workers, focusing on warmth and competence as the two core dimensions in social judgement. As predicted, older workers were perceived as less competent but warmer than younger workers. Studies 2 and 3 investigated how these stereotypes interact with job requirements to predict age bias in an experimental setting. Further, they tested if warmth- and competence-related stereotypical inferences mediate the relation between candidate age and selection bias. Results showed that age bias was robust. Older candidates were discriminated against, even if the job primarily required warmth-related qualities, and independently of evaluators' own age or professional experience in human resources. Moreover, age bias was mediated by competence-related stereotypical inferences. Age bias was also mediated by inferences related to warmth but those inferences were opposite to the highwarmth older worker stereotype identified in Study 1. Implications of the findings for theoretical approaches to age discrimination and for organizational practice designed to combat age discrimination are discussed.
\end{abstract}

In a recent international survey, workers reported experiencing age discrimination more often than other forms of discrimination (e.g. based on gender; Kelly Services, 2006). Both young and older workers felt discriminated against but rates were considerably higher for workers above age 45 than for younger workers. Moreover, despite the fact that European legislation has outlawed age discrimination at work, $58 \%$ of Europeans see age discrimination as a widespread problem in their country (European Commission, 2009). Meta-analyses show that younger workers are

Parts of this research were presented at the annual meeting of the Academy of Management, August 2010, Montréal, Canada. systematically evaluated and treated more favourably than older workers (Finkelstein, Burke and Raju, 1995; Gordon and Arvey, 2004). These figures are disquieting - especially in the light of the current ageing of the population - and call for research that investigates mechanisms that drive age discrimination.

One explanation is that ageist stereotypes reign within organizations and lead to discrimination against older workers (Shore and Goldberg, 2005). Thus, age-stereotypical inferences are thought to underlie discriminatory behaviours like lower hiring rates for equally qualified older job candidates compared to younger candidates. This is the focus of the present research. We first determined the content of stereotypes about older 
and younger workers in a survey, focusing on warmth and competence as the two core dimensions of social judgement (Fiske, Cuddy and Glick, 2007). In two experiments, we investigated how warmth and competence stereotypes interact with job requirements to predict discrimination. Moreover, we examined warmth- and competence-related stereotypical inferences as mediators of the relation between candidate age and selection bias.

This research makes three contributions. First, it elucidates the role of competence and warmth for selection bias. Competence and warmth constitute the two core dimensions in social judgement, providing fundamental clues about characteristics attributed to persons when they perform tasks and interact with others (Fiske, Cuddy and Glick, 2007). Despite their centrality for explaining discrimination against members of stereotyped groups, they have not yet received attention in organizational research on age bias (Finkelstein and Farrell, 2007). Second, by investigating stereotypical inferences as mediators of selection bias directly, this research addresses an important gap in the literature. Stereotypes are often assumed to underlie age bias, but there is little direct evidence showing that stereotypes mediate discriminatory responses towards specific older workers (Finkelstein and Farrell, 2007; Shore and Goldberg, 2005). This evidence is crucial because it provides insights into the causal mechanisms underlying age discrimination and thus potential ways to reduce it. Finally, current population ageing makes studying the impact of older worker stereotypes particularly important. If older workers are excluded based on stereotypes, this not only has detrimental consequences for a large group of potential victims (Redman and Snape, 2006) but can also affect organizational performance, e.g. by increasing the risk of personnel shortage.

\section{Older worker stereotypes}

Older worker stereotypes are simplifying, generalizing beliefs and expectancies about characteristics of older workers based on their age. Beliefs about older workers feature a rich array of associated traits and skills (Posthuma and Campion, 2009). For example, older workers are believed to have less potential for development, to be less trainable, less adaptable, less effective and less competent than younger workers; moreover, they are believed to be more costly, more reliable, more loyal, more stable, more interpersonally skilled and more prone to illness (Bird and Fisher, 1986; Gordon and Arvey, 2004; Kluge and Krings, 2008; Lyon and Pollard, 1997; McGregor and Gray, 2002; Redman and Snape, 2002; Rosen and Jerdee, 1976; Warr and Pennington, 1993). This coexistence of positive and negative associations might seem coincidental at first sight. However, recent theories on social judgement suggest that it is systematic, reflecting two fundamental dimensions: warmth or communion and competence or agency (Abele and Wojcizske, 2007; Cuddy, Fiske and Glick, 2008; Eagly, 1987; Fiske, Cuddy and Glick, 2007; Phalet and Poppe, 1997). Warmth (e.g. sincere, kind, trustworthy and their opposites) pertains to functioning in social relations. Competence (e.g. capable, skilful, intelligent and their opposites) pertains to functioning at tasks. The organization of traits into warmth and competence is functional. From an evolutionary perspective, they provide answers to two questions that are crucial to human survival: when encountering another person or group, people must determine their intent (are they friend or foe: warmth) and their ability to act on this intent (do they have the skills and competences: competence) (Fiske, Cuddy and Glick, 2007).

Warmth and competence constitute the two core dimensions in social judgement across a large array of social groups and in various cultural contexts (Cuddy and Fiske, 2002; Cuddy, Fiske and Glick, 2008; Cuddy, Norton and Fiske, 2005; Cuddy et al., 2009; Fiske et al., 2002; Phalet and Poppe, 1997). The stereotype content model (SCM) focuses on warmth and competence as underlying dimensions of group stereotypes (Fiske et al., 2002). It posits that most stereotypes are mixed, combining positive and negative elements. As a consequence, many groups are perceived as high in warmth but low in competence or vice versa. This is also true for the elderly: SCM research found that the elderly are seen as high in warmth but low in competence, based on their perceived lack of competitiveness and low status (Cuddy and Fiske, 2002; Cuddy, Norton and Fiske, 2005; Fiske et al., 2002). Importantly, warmth and competence judgements also predict the way we feel and 
behave towards members of this group (see further below).

Do high warmth/low competence stereotypes of the elderly apply to older workers? Older workers (age 50+) are considerably younger than the elderly in research on age stereotypes. These age differences may lead to differences in stereotype content. Also, being active rather than retired from the labour market might affect stereotype content, especially perceived competence. Nevertheless, prior research on beliefs about older workers suggests that, indeed, low competence is firmly associated with older workers (Posthuma and Campion, 2009). Whether elderly warmth stereotypes apply to older workers seems less clear. Some beliefs suggest positive warmth perceptions (e.g. older workers are loyal and interpersonally skilled; Warr and Pennington, 1993) whereas others suggest negative warmth perceptions (e.g. older workers are more opinionated; Craft et al., 1979). But being opinionated may be interpreted as a sign of selfconfidence and hence more closely related to competence than to warmth (Fiske et al., 2002). Taken together, positive warmth elements seem to outweigh negative ones, suggesting that, overall, older workers are perceived as higher in warmth than younger workers.

\section{Impact of older worker stereotypes}

We suggested above that older workers are stereotyped as low in competence and high in warmth. According to the SCM, this leads to two responses: low competence stereotypes are associated with feelings of disrespect and lead to exclusion, whereas high warmth stereotypes are associated with liking and trigger helping (Cuddy, Fiske and Glick, 2008). Thus, in a hiring situation, they might lead to opposite outcomes: based on low competence stereotypes, older candidates may be rejected, whereas based on high warmth stereotypes, they may be selected. Competence judgements are essential for hiring and thus low competence stereotypes are likely to systematically bias responses against older workers (Shore and Goldberg, 2005). However, selection decisions further depend on what is required within a specific role, as suggested by congruity theories of discrimination (Eagly and Diekman, 2005; Heilman, 1983). These theories posit that selection depends on the perceived (mis)match between assumed characteristics of the candidate and role requirements.

Role requirements depend on context. Accordingly, age bias is moderated by job stereotypes (Perry, 1994; Perry, Kulik and Bourhis, 1996), career stage (Lawrence, 1988) or organizational culture as shown by Diekman and Hirnisey (2007). They found that older candidates were preferred over younger candidates for a traditional, stable company whereas the opposite was true for a dynamic, rapidly growing company.

Job skill requirements might also moderate bias. Often, person-oriented or interpersonal skills (e.g. friendliness, interpersonal sensitivity, the ability to fit in) are distinguished from taskoriented or technical skills (e.g. maths, reading and writing). Person-oriented skills are linked to warmth-related, communal qualities, because both pertain to the level of functioning in social relations. Consequently, warmth stereotypes might interact with job requirements: for jobs requiring strong person-oriented qualities, the perceived match between job requirements and assumed candidate characteristics might increase for older candidates. Put differently, for jobs requiring person-oriented qualities, positive warmth stereotypes might offset the impact of negative competence stereotypes and thus reduce age bias.

Empirical evidence supports this assumption. For example, discrimination against women, a group perceived as higher in warmth than in competence (Eagly and Mladinic, 1989), is less likely for jobs requiring communal qualities compared to jobs requiring task-oriented qualities (Eagly and Karau, 2002; Eagly and Sczesny, 2008). Similar patterns hold for immigrant candidates belonging to national groups that differ in liking (i.e. warmth) (Krings and Olivares, 2007).

\section{Stereotypical inferences as mechanisms underlying age discrimination}

Ample evidence suggests that stereotypical inferences about a target person encourage bias. For example, raters who hold strong stereotypical beliefs about older workers show age bias when evaluating candidates for age-typed jobs (Perry, Kulik and Bourhis, 1996) or when making 
recommendations for terminating an employee (Rupp, Vodanovich, and Credé, 2006). These studies suggest that age stereotypes underlie discrimination but the evidence is indirect, as it does not empirically demonstrate a direct relation between participants' endorsement of stereotypical beliefs and their actions. Direct evidence is scant (Finkelstein and Farrell, 2007). Diekman and Hirnisey (2007) found that perceived adaptability mediated the tendency to prefer younger over older workers for a dynamic company. Similarly, Chiu et al. (2001) found that beliefs about older and younger workers' adaptability mediated intentions regarding several outcomes (e.g. training, promotion). Both studies provide important evidence for the notion that age stereotypes drive bias. Yet, they focused on specific components of the older worker stereotype that seem most closely related to the competence dimension. To cover stereotypes more broadly and account for their multidimensional nature, we explored the mediational role of both competenceand warmth-related inferences.

\section{Overview of the studies and hypotheses}

We conducted three studies. In Study 1, we determined warmth and competence stereotypes about older and younger workers, hypothesizing the following.

H1: Older workers are perceived as lower in competence and higher in warmth than younger workers.

Studies 2 and 3 examined the role of warmth and competence stereotypes for age-based discrimination in an experimental setting. Using samples of business students (Study 2) and human resource (HR) professionals (Study 3), we expected participants' selection decisions to systematically disfavour the older candidate, based on low competence stereotypes.

H2: Older candidates have fewer chances to be selected for an interview than younger candidates.

Based on congruity theories of discrimination, we further expected job requirements to moderate the above-described main effect. Specifically, candidate age and job requirements were expected to interact, such that discriminatory responses toward older candidates are attenuated when the job requires warmth-related, personoriented qualities, compared to when the job requires task-oriented qualities. Note that we did not expect reversed discrimination, i.e. a preference for older candidates for jobs requiring person-oriented qualities. However, for personoriented job requirements, we expected positive warmth stereotypes to counteract the influence of negative competence stereotypes.

H3: The difference at selection between older and younger candidates is smaller (or nonexistent) if the job primarily requires personoriented qualities than if it primarily requires task-oriented qualities.

Finally, heeding calls for research that directly examines mechanisms underlying selection bias (e.g. Finkelstein and Farrell, 2007), we investigated the mediational role of stereotypical inferences for age bias. We focused on competence- and warmthrelated traits and skills that are crucial in a work environment, expecting the following.

H4: Age-stereotypical inferences related to warmth and competence mediate the relation between candidate age and intentions to interview.

\section{Study 1}

\section{Method}

Participants. Participants were 109 business students (43 women; mean age 20.78 years, $\mathrm{SD}=1.52$ ) participating in a course on marketing at the University of Lausanne, Switzerland.

Procedure and questionnaire. The questionnaire (in French) was part of a larger testing session. Participants rated several social target groups including older workers (age 50 and older) and younger workers (age 30 and younger) on warmth and competence traits. We chose age 50 for older workers because, at this age, age discrimination is frequent (Chiu et al., 2001; Kelly Services, 2006). Ratings were made for groups of older and younger workers in general. Adopting instructions typically used in SCM research, participants were asked to rate, for each trait, how they believed that a certain group is considered by Swiss society. These instructions 
Table 1. Summary of factor analysis results for warmth and competence items (Study 1)

\begin{tabular}{lccccc}
\hline Item & \multicolumn{2}{c}{ Older workers } & & \multicolumn{2}{c}{ Younger workers } \\
\cline { 2 - 3 } \cline { 5 - 6 } & Warmth & $\begin{array}{c}\text { Compe- } \\
\text { tence }\end{array}$ & & Warmth & $\begin{array}{c}\text { Compe- } \\
\text { tence }\end{array}$ \\
\hline Capable & 0.12 & 0.69 & & 0.12 & 0.80 \\
Efficient & -0.27 & 0.70 & & 0.15 & 0.75 \\
Competent & 0.14 & 0.79 & & -0.04 & 0.78 \\
Intelligent & 0.21 & 0.51 & & 0.54 & 0.37 \\
Skilled & -0.04 & 0.64 & & 0.04 & 0.74 \\
Sincere & 0.60 & 0.15 & & 0.69 & 0.04 \\
Warm & 0.77 & -0.03 & & 0.73 & -0.12 \\
Good-natured & 0.80 & -0.14 & & 0.69 & 0.04 \\
Benevolent & 0.70 & 0.18 & & 0.78 & 0.06 \\
Amicable & 0.77 & 0.04 & & 0.71 & 0.05 \\
Eigenvalue & 2.87 & 2.26 & & 3.33 & 2.11 \\
\% of variance & $28.7 \%$ & $22.6 \%$ & & $33.2 \%$ & $21.2 \%$ \\
Cronbach's alpha & 0.78 & 0.70 & & 0.77 & 0.76 \\
\hline
\end{tabular}

focus on societal stereotypes as culturally shared knowledge and limit the impact of social desirability on responses (Cuddy, Fiske and Glick, 2008).

Scales contained five traits each, covering the central characteristics of competence and warmth (see Fiske et al., 2002): capable, efficient, competent, intelligent, skilled for perceived competence, and sincere, warm, good-natured, benevolent, amicable for perceived warmth (five-point response scales: $1=$ not at all, $5=$ very much). The order of the target groups was varied. After completing the questionnaire (about 20 minutes), participants were debriefed. Main results were discussed in class a few weeks later.

\section{Results and discussion}

To examine whether items reflected the dimensions of warmth and competence for both target groups, we conducted two exploratory factor analyses with varimax rotation, specifying two factors. Taken together, the results (see Table 1) suggest that the items reliably measured the two dimensions, for both target groups. ${ }^{1}$ We thus

\footnotetext{
${ }^{1}$ For younger workers, the factor loading of the item 'intelligent' on the competence factor was lower than the loadings of the remaining four competence items. Moreover, this item also loaded on the warmth factor. We thus ran the analyses reported in the next section twice, once with competence scores including this item (full five-item competence scale) and once with competence scores excluding it (reduced four-item competence
}

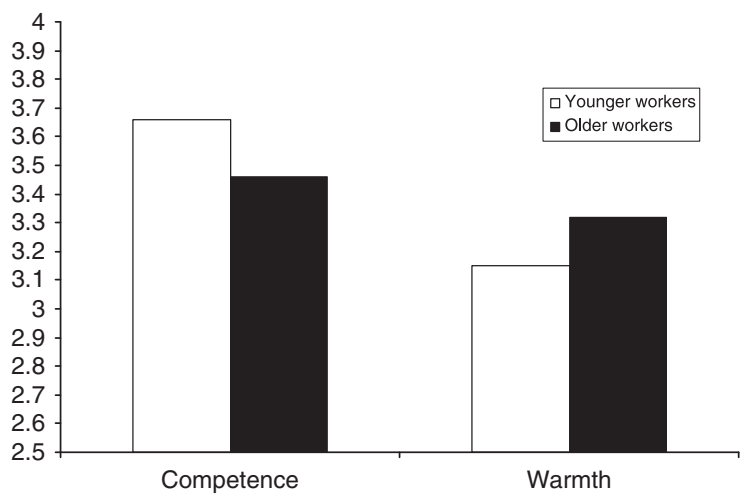

Figure 1. Warmth and competence stereotypes of younger and older workers (Study 1).

Note: Ratings were done on five-point scales, with higher scores indicating stronger stereotypes.

created competence and warmth scores by averaging across the corresponding five items. ${ }^{2}$

Results of the paired-samples tests comparing the score means showed that older workers $(\mathrm{M}=3.46, \quad \mathrm{SD}=0.56)$ were rated lower in competence than younger workers $(\mathrm{M}=3.66$, $\mathrm{SD}=0.62), \mathrm{t}(108)=-2.44, \mathrm{p}=0.02$. Moreover, older workers $(\mathrm{M}=3.32, \mathrm{SD}=0.58)$ were rated as higher in warmth than younger workers $(\mathrm{M}=3.15, \quad \mathrm{SD}=0.59), \mathrm{t}(108)=2.27, \quad \mathrm{p}=0.02$ (see Figure 1). Both groups were perceived as being more competent than warm but the difference between warmth and competence ratings was greater for younger $(0.51)$ than for older workers $(0.14), \mathrm{t}(108)=3.22, \mathrm{p}<0.01$. Thus, albeit differences between ratings of younger and older workers did not appear large at first sight, they were significant and in line with our predictions. Results support Hypothesis 1, i.e. older workers were perceived as warmer and as less competent than younger workers. This finding is important because participants of the following studies evaluated younger and older job candidates and then selected one. In this context, comparative stereotypes are highly pertinent.

scale). Results were similar to those obtained with the full five-item scale.

${ }^{2}$ Preliminary analyses showed no effects of participant gender. The same was true for Studies 2 and 3. Thus, gender was not included in the main analyses of the three studies. 


\section{Study 2}

\section{Method}

Participants and procedure. Participants were 101 business students $(54.3 \%$ women; mean age $21.92, \mathrm{SD}=1.75)$ taking part in a course on $\mathrm{HR}$ management at the University of Lausanne, Switzerland. The study took place at the beginning of the semester. Participants were informed that the study was about the quality of résumés on which their opinion as future HR professionals was needed. After completing the ratings (about 25 minutes), they were debriefed and main results were discussed in class some weeks later.

Study design and independent variables. The experiment followed a 2 (candidate age: young or old) $\times 2$ (job requirements: person-oriented or task-oriented) $\times 2$ (order of candidate ratings: young then old, old then young) mixed design, with candidate age as a within-subjects factor ${ }^{3}$ and skill requirements and rating order as between-subjects factors.

Participants received a fictitious job advertisement, two fictitious résumés and a questionnaire (in French). The job advertisement was modelled after advertisements posted in local newspapers or on on-line forums. It contained the job title (travel agent), a job description outlining the main responsibilities, and the required educational degree (apprenticeship, certified by a federal agency). We chose an age-neutral position (travel agent) to render the job skill requirement manipulation more effective. Previous research found that the job of a travel agent is perceived to be equally suitable for younger and older persons (Finkelstein, Burke and Raju, 1995). We confirmed these perceptions in a pre-test with 29

\footnotetext{
${ }^{3}$ In Studies 2 and 3, age was manipulated as a withinsubjects factor because candidates are usually selected from a pool of applicants and compared to others. Thus, relative decisions (as taken in a within-subjects design) seem to resemble organizational reality more closely than absolute decisions (as taken in a between-subjects design). Nonetheless, one might suspect that manipulating age as a within-subjects factor increases age effects, by rendering age more salient. However, the opposite might also be true. Salience may lead to more cautious behaviour in participants. Indeed, a recent meta-analysis revealed that age bias in within-subject designs is less pronounced than in between-subject designs (Gordon and Arvey, 2004).
}

undergraduate students (mean age $=21.93$; $\mathrm{SD}=2.20)$ who rated a series of jobs on several dimensions. On a scale from 1 (job is only suitable for younger people) to 7 (job is only suitable for older people), 21 participants $(72.4 \%)$ chose option 4 (age is not important) $(\mathrm{M}=3.76$, $\mathrm{SD}=0.58$ )

Job requirements were manipulated by specifying six responsibilities in the job description. In the person-oriented condition, all responsibilities were person-oriented, requiring substantial personal interactions (e.g. work closely with the team at the agency; participate in team meetings with other branches). In the task-oriented condition, all responsibilities were task-oriented, involving administrative work that required only very limited personal interactions (e.g. administer bills and local accounting, take stock for annual stocktaking).

Candidate age (29 or 50 ) was indicated by date of birth on the résumés. ${ }^{4}$ Résumés were modelled after résumés posted on local internet advice websites. They contained the candidates' educational and professional history and demographic information. Both candidates were male, married and Swiss. They had the required educational degree. The older candidate had 14 years and the younger candidate eight years of professional experience as a travel agent. Both had worked in three different agencies. The older candidate had additional experience working as a sales-person in book shops, at the beginning of his career. ${ }^{5}$

\footnotetext{
${ }^{4}$ As mentioned earlier, we chose age 50 for older candidates because, at this age and above, age discrimination is likely. Moreover, we chose this age to limit the impact of financial considerations on participants' selection decisions. Financial considerations (e.g. high investment costs with little return) play a role for hiring decisions concerning older job applicants (Finkelstein, Higgins and Clancy, 2000). However, a 50-yearold candidate can be expected to stay at least 15 years in a company after being hired (the official retirement age in Switzerland is 65). Thus, for participants in this research, investment costs and returns on investment concerning the older applicant should have been relatively balanced.

${ }^{5}$ Note that from a methodological point of view it might be desirable to keep professional experience constant across candidates, to avoid confounding age and experience. In reality, the two are almost always confounded because older candidates typically have more experience than younger candidates. In fact, a 50year-old candidate with the same experience as a 30year-old candidate might even look unrealistic to
} 
Participants indicated their ratings in a separate questionnaire. Within the questionnaire, rating order was counterbalanced: half of the participants received a questionnaire in which rating scales for the older candidate were followed by those for the younger candidate; the other half received a questionnaire with scales in the reverse order. The multivariate effect of rating order on the dependent variables was nonsignificant, Hotelling's trace $=0.14$. Thus, rating order was not included in the main analyses.

After returning the study materials, participants received a sheet of paper containing questions on demographics and manipulation checks.

Dependent variables. Selection was assessed with interview intentions ('Would you invite the candidate to a job interview?' Seven-point response scale: $1=$ not at all, $7=$ absolutely) and final selection decisions ('If you could invite only one of the two candidates to a job interview, who would you choose?' - binary choice).

Stereotypical inferences were assessed with four items (seven-point response scales: $1=\mathrm{do}$ not agree at all, $7=$ totally agree). We focused on competence- and warmth-based inferences that refer to ways these basic dimensions express themselves in a work environment. Warmthrelated inferences were assessed with the following items: 'The candidate is a good team-worker', 'The candidate probably gets along well with colleagues' $\left(\alpha_{\text {young }}=0.64, \alpha_{\text {old }}=0.80\right)$. Competence-related inferences were assessed with 'The candidate is a high-performer' and 'The candidate has the necessary competence to succeed in the job' $\left(\alpha_{\text {young }}=0.69, \alpha_{\text {old }}=0.67\right)$.

Manipulation checks. The effectiveness of the age manipulation was tested with one of four open-ended questions about candidates' demographics (for the remaining questions, see further below) where participants were asked to indicate the candidates' age. To assure that participants recognized that the candidates fulfilled the formal

evaluators. Thus, for the construction of the résumés, we faced a trade-off between study realism and methodological rigour. In this case, we opted for the latter, not least because in Study 3 the résumés were presented to HR professionals for whom realism of the material may play an even more important role than for students. requirements for the job, another open-ended question asked participants to indicate the candidates' highest educational degree. The remaining two demography questions were filler questions. Further, we included a series of control items on perceptions of qualifications and résumé quality, to more readily assure that differences in selection and stereotypical ratings of the older and the younger candidates could be attributed to candidate age and not to perceived differences in qualifications or overall quality of the résumés. In other words, we expected the following measures to be unaffected by the age manipulation. Three items assessed participants' perception of the candidates' overall qualifications for the job: 'The candidate is sufficiently qualified for the job', 'The candidate completed the right training for the job', 'The candidate has the necessary professional experience for the job' $\left(\alpha_{\text {young }}=0.76, \alpha_{\text {old }}=0.79\right)$. Two items assessed the perceived quality of the candidates' résumés: 'The résumé contains the necessary elements', 'The résumé is complete' $\left(\alpha_{\text {young }}=0.81, \alpha_{\text {old }}=0.79\right)$. Responses were indicated on seven-point scales $(1=$ do not agree at all, $7=$ totally agree $)$.

\section{Results}

Manipulation checks. Two participants did not answer the question about the candidates' age and were excluded from the analyses. The remaining 99 participants reported the candidates' age correctly. Four participants did not answer the question about the candidates' educational degree correctly and were excluded. The final sample consisted of 95 participants, with 49 participants in the task-oriented condition and 46 participants in the person-oriented condition.

Ratings on the measures of perceived qualification and perceived quality of résumé were correlated, for both candidates: $r_{\text {old }}=0.39$ and $r_{\text {young }}=0.46$, both $p$ values $<0.001$. We thus performed a 2 (candidate age) $\times 2$ (skill requirements) multivariate analysis of variance (MANOVA), with skill requirements as betweensubjects factor, candidate age as a within-subjects factor, and perceived qualification and résumé quality as dependent variables. Results showed that ratings did not differ between candidates (overall qualifications: $\mathrm{M}_{\text {young }}=5.52, \mathrm{SD}_{\text {young }}=$ $0.78, \mathrm{M}_{\mathrm{old}}=5.68, \mathrm{SD}_{\mathrm{old}}=0.89$; résumé quality: 
$\mathrm{M}_{\text {young }}=4.94, \quad \mathrm{SD}_{\text {young }}=1.26, \quad \mathrm{M}_{\text {old }}=4.91$, $\left.\mathrm{SD}_{\text {old }}=1.31\right)$, Wilks's $\lambda=0.97, \mathrm{~F}(2,91)=1.31$, ns. Also, none of the other effects were significant.

Selection. A 2 (candidate age) $\times 2$ (skill requirements) ANOVA with candidate age as withinsubjects factor and job requirements as betweensubjects factor revealed that, consistent with Hypothesis 2, participants reported stronger intentions to interview the young candidate $(\mathrm{M}=5.79, \mathrm{SD}=0.98)$ than the older candidate $(\mathrm{M}=5.02, \quad \mathrm{SD}=1.31), \quad \mathrm{F}(1, \quad 90)=24.62, \quad \mathrm{p}<$ 0.001 , partial $\eta^{2}\left(\eta_{p}{ }^{2}\right)=0.22$ (see Table 2, upper part). None of the other effects were significant. Thus, contrary to Hypothesis 3, there was no interactive effect of candidate age and job requirements. When asked to choose between the candidates, $74 \%$ chose the young candidate, $\chi^{2}(1, \mathrm{~N}=91)=22.25, \mathrm{p}<0.001$. To analyse the effects of job requirements and candidate age on selection decisions, we conducted a logistic regression. We coded selection decisions as 0 for selected younger candidate and 1 for selected older candidate, and regressed them on job requirements. Contrary to our expectations (see Hypothesis 3), job requirements had no impact on the probability to select the older candidate, odds ratio $(\mathrm{OR})=0.73,95 \%$ confidence interval (95\% CI) $0.28-1.88$, ns.

Stereotypical inferences. Stereotypical inferences related to warmth and competence (hereafter referred to as perceived warmth and competence) were expected to mediate the relation between candidate age and interview intentions (Hypothesis 4). Candidate age was manipulated as a withinsubjects factor. To show within-subjects mediation, two conditions have to be met: (1) there is a significant difference in the mediator and (2) this difference predicts the difference in the dependent variable (Judd, Kenny and McClelland, 2001). Because the same variable may both mediate and moderate the relation between the predictor and the outcome variable, mediation and moderation are analysed simultaneously when testing condition (2) (see further below).

To test the first condition, we analysed the effects of candidate age on stereotypical trait ratings by conducting two 2 (candidate age) $\times 2$ (job requirements) ANOVAs with competence and warmth respectively as dependent variable. Results showed that the younger candidate was perceived as more competent $(\mathrm{M}=5.17, \mathrm{SD}=0.68), \mathrm{F}(1$, 92) $=6.43, \mathrm{p}<0.01, \eta_{p}^{2}=0.07$, and, surprisingly,

Table 2. Candidate ratings and selection decisions as a function of candidate age and job requirements in Studies 2 (upper part) and 3 (lower part)

\begin{tabular}{|c|c|c|c|c|}
\hline \multirow[t]{2}{*}{ Candidate evaluations } & \multicolumn{2}{|c|}{ Younger candidate } & \multicolumn{2}{|c|}{ Older candidate } \\
\hline & $\begin{array}{l}\text { Person-oriented job } \\
\text { requirements }\end{array}$ & $\begin{array}{l}\text { Task-oriented job } \\
\text { requirements }\end{array}$ & $\begin{array}{l}\text { Person-oriented job } \\
\text { requirements }\end{array}$ & $\begin{array}{c}\text { Task-oriented job } \\
\text { requirements }\end{array}$ \\
\hline \multicolumn{5}{|l|}{ Study 2 ( $n=95$ business students) } \\
\hline \multicolumn{5}{|l|}{ Inferences } \\
\hline Competence & $5.27 \mathrm{a}(0.61)$ & 5.07 a $(0.73)$ & $4.96_{\mathrm{b}}(0.84)$ & $4.86_{b}(0.86)$ \\
\hline Warmth & $4.62 \mathrm{a}(0.75)$ & $4.25_{\mathrm{a}}(0.73)$ & $4.20_{\mathrm{b}}(0.73)$ & $4.17_{\mathrm{b}}(1.01)$ \\
\hline \multicolumn{5}{|l|}{ Outcomes } \\
\hline Interview intentions & $5.73_{\mathrm{a}}(1.10)$ & $5.85_{\mathrm{a}}(0.86)$ & $5.02_{\mathrm{b}}(1.51)$ & $5.01_{\mathrm{b}}(1.10)$ \\
\hline $\begin{array}{l}\text { Number of participants who } \\
\text { selected the candidate }\end{array}$ & 35 & 33 & 10 & 13 \\
\hline \multicolumn{5}{|l|}{ Study 3 ( $n=88$ HR professionals) } \\
\hline \multicolumn{5}{|l|}{ Inferences } \\
\hline Competence & $5.12_{\mathrm{a}}(0.79)$ & $5.17_{\mathrm{a}}(0.91)$ & $4.65_{\mathrm{b}}(0.84)$ & $4.99_{\mathrm{b}}(1.05)$ \\
\hline Warmth & $4.45_{\mathrm{a}}(0.72)$ & $4.40_{\mathrm{a}}(0.70)$ & $4.33_{\mathrm{b}}(0.64)$ & $4.17_{\mathrm{b}}(0.49)$ \\
\hline \multicolumn{5}{|l|}{ Outcomes } \\
\hline Interview intentions & $5.69_{\mathrm{a}}(0.84)$ & $5.50_{\mathrm{a}}(1.19)$ & $4.95_{\mathrm{b}}(1.45)$ & $4.85_{\mathrm{b}}(1.49)$ \\
\hline $\begin{array}{l}\text { Number of participants who } \\
\text { selected the candidate }\end{array}$ & 35 & 33 & 13 & 7 \\
\hline
\end{tabular}

Notes. For all variables but selection decisions, means with standard deviations in parentheses are shown. Inferences and interview intention ratings were made on seven-point scales, with higher values indicating more positive evaluations or stronger intentions to interview. Means in the same row that do not share the same subscripts differ significantly at $\mathrm{p}<0.05$. For Study 2 , numbers in the last row add up to 91 because four of the 95 participants did not indicate their choice. 
as warmer $(\mathrm{M}=4.43, \mathrm{SD}=0.76)$ than the older candidate $(\mathrm{M}=4.91, \mathrm{SD}=0.85$ and $\mathrm{M}=4.18$, $\mathrm{SD}=0.88$, respectively), $\mathrm{F}(1,91)=4.18, \mathrm{p}=0.04$, $\eta_{p}{ }^{2}=0.04$ (see Table 2, upper part). None of the other effects were significant.

To test the second condition, we used warmth and competence difference scores as predictors of differences in interview intentions in two separate regression analyses. Simultaneously, we entered warmth and competence sum scores respectively as predictors in these analyses to test if competence and warmth acted as moderators of the relation between age and interview intentions (e.g. by amplifying the effect of age on selection) (see Judd, Kenny and McClelland, 2001).

The regression analysis with competence difference and sum scores (centred) as predictors revealed that differences in perceived competence predicted differences in interview intentions, $\mathrm{B}=0.83$, $\mathrm{SE}=0.14, \mathrm{p}<0.001, \mathrm{~F}(2,89)=19.08, \mathrm{p}<0.001$. The intercept remained significant, $-0.55, \mathrm{p}<$ 0.001 , reflecting the residual effect of candidate age on outcomes (Judd, Kenny and McClelland, 2001). Thus, inferences about competence partially mediated the relation between age and interview intentions. The competence sum score was unrelated to differences in interview intentions, $\mathrm{B}=$ $-0.11, \mathrm{SE}=0.11$, indicating that perceived competence did not moderate the relation between candidate age and interview intentions.

The regression analysis with warmth difference and sum scores (centred) as predictors revealed that differences in warmth judgements predicted differences in interview intentions, $\mathrm{B}=0.27$, $\mathrm{SE}=0.13, \mathrm{p}=0.03$, with the overall regression model approaching significance, $\mathrm{F}(2,88)=2.54$, $\mathrm{p}=0.08$. The intercept was significant, -0.75 , $\mathrm{p}<0.001$, indicating partial mediation. The warmth sum score was unrelated to differences in interview intentions, $\mathrm{B}=-0.12, \mathrm{SE}=0.14$, ns, showing that perceived warmth did not moderate the effect of age on interview intentions. In sum, Hypothesis 4 was partially supported.

\section{Discussion}

Study 2 revealed consistent effects of candidate age on selection, to the older candidate's disfavour. Moreover, it provided evidence for the underlying mechanism of this bias, by demonstrating that competence-related stereotypical inferences mediate interview intentions. Unex- pectedly, age bias was independent of job requirements. Study 1 found that older workers were perceived as warmer but less competent than younger workers. However, contrary to our hypothesis, discrimination against older candidates was not reduced when the job required primarily warmth-related, communal qualities. Further, surprisingly, the older candidate was perceived as less warm than the younger candidate and hence opposite to the high warmth older worker stereotype identified in Study 1. Nevertheless, results suggested that inferences about the candidate's warmth-related qualities partially mediate the relation between age and selection. Several explanations for these findings seem possible. Because they were unpredicted, we sought to replicate them in a second experiment (Study 3), using a different sample.

Evaluator's young age and lack of professional experience may have amplified age bias in Study 2. Stereotypical beliefs about older workers become more positive with increasing age of the evaluator (Finkelstein, Burke and Raju, 1995; Hassell and Perrewe, 1995; Kluge and Krings, 2008). Also, experienced professionals (e.g. supervisors) evaluate older workers less negatively than students do (Gordon and Arvey, 2004). Hence, in Study 3, we tested our hypotheses with a sample of HR professionals.

\section{Study 3}

\section{Method}

Participants and procedure. Participants were 88 professionals $(52.3 \%$ women) working in HR departments of various organizations in the French-speaking region of Switzerland. They were between 21 and 65 years old $(\mathrm{M}=37.56$, $\mathrm{SD}=10.31)$, with an average tenure of 6.69 years $(\mathrm{SD}=7.32)$. Their experience in $\mathrm{HR}$ ranged from half a year to 30 years $(\mathrm{M}=8.21, \mathrm{SD}=6.59)$. They were contacted by a research assistant who explained that the university was seeking the help of HR experts to give their opinion on the quality of résumés. If the person agreed to participate, $\mathrm{s}$ / he received a job advertisement and two résumés (materials were identical to those of Study 2) and a questionnaire, together with a pre-paid envelope addressed to the university. Participants who had indicated on the questionnaire that they were interested in receiving the study's results were 
sent a summary of the results, together with a detailed description of the study's rationale.

Study design and independent variables. The experiment had a 2 (candidate age: young or old) $\times 2$ (job requirements: person-oriented or taskoriented) mixed design, with candidate age manipulated as a within-subjects factor and skill requirements as a between-subjects factor.

Dependent variables. For selection and stereotypical inferences, all scales used in Study 2 were included in the questionnaire (for details on the items, see above): interview intentions (one item), selection decisions (one, binary item), perceived competence (two items; $\alpha_{\text {young }}=0.85, \alpha_{\text {old }}=0.82$ ) and perceived warmth (two items; $\alpha_{\text {young }}=0.84$, $\alpha_{\text {old }}=0.74$ ).

Manipulation checks. All manipulation checks used in Study 2 were included (for details, see above): candidate age and educational degree (open-ended questions), perceived qualification (three items; $\alpha_{\text {young }}=0.88, \alpha_{\text {old }}=0.64$ ) and résumé quality (two items; $\alpha_{\text {young }}=0.69, \alpha_{\text {old }}=0.76$ ).

Control variables. Because evaluators' own age and professional experience may influence evaluations and selection decisions, age and experience in HR (in years) were included as control variables.

\section{Results}

Manipulation checks. All participants correctly reported the candidates' age and educational degree (the one that was needed to qualify for the job). Participants' ratings on the measures of perceived qualification and perceived quality of résumé were correlated, for both candidates, $\mathrm{r}_{\text {old }}=0.35, \mathrm{r}_{\text {young }}=0.45$, both $\mathrm{p}$ values $<0.01$. A 2 (candidate age) $\times 2$ (skill requirements) MANOVA, with candidate age as a withinsubjects factor, skill requirements as a betweensubjects factor and perceived qualifications and résumé quality as dependent variables showed that ratings did not differ between the two candidates (overall qualifications: $\mathrm{M}_{\text {young }}=5.68$, $\mathrm{SD}_{\text {young }}=0.97 ; \quad \mathrm{M}_{\text {old }}=5.70, \quad \mathrm{SD}_{\text {old }}=1.00 ;$ résumé quality: $\mathrm{M}_{\text {young }}=4.71, \quad \mathrm{SD}_{\text {young }}=1.21$;
$\left.\mathrm{M}_{\text {old }}=4.70, \quad \mathrm{SD}_{\text {old }}=1.25\right)$, Wilk's $\Lambda(0.99), \quad \mathrm{F}(2$, $85)=0.06$, ns. All remaining effects were also non-significant. To test if evaluators' own age or HR experience had an impact on the results, we repeated the MANOVA above, introducing participant age and HR experience as covariates. The analysis yielded no significant effects, all $\mathrm{F}<1.19$, ns. Thus, evaluator age and HR experience did not alter the results reported above.

Selection. A 2 (candidate age) $\times 2$ (job requirements) ANOVA with candidate age as withinsubjects factor and skill requirements as betweensubjects factor showed that participants reported stronger intentions to interview the younger candidate than the older candidate, $\mathrm{F}(1,86)$ $=21.40, \mathrm{p}<0.001, \eta_{p}{ }^{2}=0.20$ (see Table 2, lower part). All other effects were non-significant. When asked which of the two candidates they would choose for an interview, $77 \%$ of the participants selected the younger candidate, $\chi^{2}(1, \quad \mathrm{~N}=88)=32.69, \mathrm{p}<0.001$. Four participants did not indicate their choice. To test the effects of skill requirements and candidate age on selection decisions, we conducted a logistic regression, with selection decisions as dependent variable (coded as 0 for selected younger candidate and 1 for selected older candidate). Job requirements had no impact on the probability to select the older candidate, $\mathrm{OR}=0.51,95 \% \mathrm{CI}$ $0.18-1.44$, ns.

To test whether evaluators' age or experience in HR influenced the pattern of results reported above, we re-conducted the analyses, introducing evaluator age or years of experience in HR as a covariate. For interview intentions, introducing evaluator age as a covariate reduced the effect of candidate age but candidate age remained a significant predictor, $\mathrm{F}(1,85)=4.98, \mathrm{p}=0.03$, $\eta_{p}{ }^{2}=0.06$. Similarly, when using HR experience as a covariate, the effect of candidate age on interview intentions was reduced but remained significant, $\mathrm{F}(1,86)=14.08, \mathrm{p}<0.001, \eta_{p}{ }^{2}=0.14$. Thus, controlling for evaluator age and HR experience attenuated discriminatory responses but the effects of candidate age remained significant. Neither evaluator age nor HR experience had a direct effect on interview intentions.

To test the impact of evaluator age and HR experience on selection decisions, we conducted a logistic regression with selection decisions as dependent variable (coded as 0 for selected 
younger candidate and 1 for selected older candidate) and evaluator age, HR experience and job requirements as predictors. Evaluator age emerged as the only significant predictor, indicating that the probability of selecting the older candidate increased with increasing age of the evaluator, $\mathrm{OR}=1.12,95 \%$ CI $1.02-1.20$, $\mathrm{p}=0.02$. To further explore this effect, we divided the sample into five age groups, creating categories that each spanned ten years: $20-29$ years $(\mathrm{n}=25), 30-39$ years $(\mathrm{n}=29), 40-49(\mathrm{n}=21), 50$ 59 years $(n=29), 60-65$ years $(n=4$; the oldest participant was 65 years old). Selection rates for the older candidate were similarly low in the three younger age groups $(20-29$, four out of $25 ; 30-39$, five out of 29; 40-49, four out of 21). Among the participants aged 50-59 years old, four out of nine selected the older candidate. All four of the participants aged 60-65 years old selected the older candidate. Sample sizes are small for the upper age categories so results should be interpreted with great caution. Nevertheless, it is interesting to note that age bias was no longer observed or turned into older worker favouritism only for participants who were equal in age (i.e. 50 ) or older than the older job candidate himself. This suggests that the significant effect of evaluator age found in the logistic regression reported above is mainly driven by selection decisions of evaluators having the same age as or older than the older candidate.

In sum, results show that selection decisions were independent of $\mathrm{HR}$ experience and to a limited extent influenced by evaluators' own age. Further, they largely replicate those found for Study 2, supporting Hypothesis 2 and disconfirming Hypothesis 3.

Stereotypical inferences. We tested if stereotypical inferences related to warmth and competence (hereafter referred to as perceived warmth and competence) mediate the relation between candidate age and interview intentions, following the procedure outlined above (see Judd, Kenny and McClelland, 2001). The 2 (candidate age) $\times 2$ (skill requirements) ANOVA showed that the younger candidate was perceived as more competent, $\mathrm{F}(1,86)=13.40, \mathrm{p}<0.001, \eta_{p}{ }^{2}=0.14$, and warmer than the older candidate, $\mathrm{F}(1,86)$ $=6.95, \mathrm{p}=0.01, \eta_{p}{ }^{2}=0.08$ (see Table 2, lower part), replicating the results of Study 2 and fulfilling condition (1) of the mediation analysis.
We conducted two regression analyses to test condition (2) (for details on the procedure, see above). Results of the first analysis revealed that differences in perceived competence predicted differences in interview intentions, $\mathrm{B}=1.10$, $\mathrm{SE}=0.14, \mathrm{p}<0.001, \mathrm{~F}(2,85)=31.1, \mathrm{p}<0.001$. The intercept remained significant, -0.34 , $\mathrm{p}<0.01$, indicating partial mediation. The competence sum score (centred) was unrelated to interview intentions, $\mathrm{B}=-0.09, \mathrm{SE}=0.07, \mathrm{~ns}$, demonstrating that perceived competence did not moderate the effect of candidate age on interview intentions. Similarly, results of the second analysis showed that differences in perceived warmth predicted differences in interview intentions, $\mathrm{B}=0.94, \mathrm{SE}=0.23, \mathrm{p}<0.001, \mathrm{~F}(2,85)=8.32$, $\mathrm{p}<0.001$. Again, the intercept was significant, $-0.53, \mathrm{p}<0.001$, indicating partial mediation. The warmth sum score (centred) was unrelated to interview intentions, $\mathrm{B}=0.05, \mathrm{SE}=0.13$, $\mathrm{ns}$, indicating that perceived warmth did not moderate the effect of age on intentions to interview. In sum, results lend partial support to Hypothesis 4 .

\section{Discussion}

The results of Study 3 provided further evidence that stereotypical inferences related to competence underlie age bias at selection. Bias was robust, i.e. it was mostly independent of evaluators' own age or HR experience, even though evaluators' own age attenuated age bias to some extent. As in Study 2, bias was also mediated by inferences related to warmth but those inferences were opposite to the high warmth older worker stereotype identified in Study 1. Results and their implications are discussed below.

\section{General discussion}

The purpose of this research was to study warmth and competence perceptions as explanations of age-based employment discrimination. Warmth and competence are the two core dimensions in social judgement, reflecting perceived levels of functioning in relationships with other people and at tasks. They underlie perceptions of various social groups across various cultural contexts (Cuddy et al., 2009; Fiske et al., 2002) but have not yet been investigated in organizational research on age bias. Study 1 showed that 
older workers were perceived as less competent but warmer than younger workers. This finding suggests that the puzzling array of positive and negative beliefs about older workers revealed in previous research is systematic: many beliefs can be categorized as high warmth (e.g. older workers are loyal) or low competence (e.g. older workers are inefficient). However, despite the fact that these stereotypes contain a positive element (high warmth) they can be detrimental. Assigning older workers incompetence but socially desirable attributes allows evaluators to exclude them (e.g. from employment) without experiencing discomfort (Fiske et al., 2002; see also Finkelstein and Farrell, 2007).

Drawing on congruity models of discrimination, Studies 2 and 3 tested if warmth and competence stereotypes interact with job requirements to predict age discrimination at selection. Results revealed consistent bias against older applicants. Across two experimental studies, both HR professionals and business students selected younger candidates more readily and more frequently for an interview than older candidates. This bias was mediated by inferences related to competence and warmth, providing direct evidence for the mechanisms underlying age bias at selection and thus addressing an important gap in research in this domain (Finkelstein and Farrell, 2007; Shore and Goldberg, 2005).

Competence-related inferences about the candidates corresponded to the older worker low competence stereotype identified in Study 1. Surprisingly, warmth-related inferences were opposite to the older worker warmth stereotype identified in Study 1: despite the fact that older workers in general were perceived as high in warmth, older job candidates in the scenario were perceived as less warm than younger candidates. Also, contrary to our expectations, discrimination was independent of job requirements related to warmth. We had expected high warmth perceptions to attenuate bias against older candidates if the job required warmth-related qualities. Two explanations of these findings seem plausible. First, perhaps belonging to a group that is perceived as high in warmth does not mean that one is perceived as successful in personal interactions at work. Possibly, many social interactions at work (e.g. with clients) are perceived as depending primarily on strategic use of interpersonal skills, with the purpose of influencing interaction partners in an outcomeoriented manner. Consequently, interpersonal skills may be more closely related to perceived competence than to warmth. Indeed, in both studies, competence and warmth ratings of the candidates were positively correlated ( $\mathrm{r}$ values between 0.32 and $0.44, \mathrm{p}<0.01$ ). However, these relations may also be due to halo effects and disappear if the impact of other dimensions is controlled for (e.g. valence; Suitner and Maass, 2008). Second, both candidates were depicted (and perceived) as being well-qualified. Therefore, the older candidate may have appeared as inconsistent with the older worker low competence group stereotype, i.e. as more competent than his age group. As a consequence, he might have been denigrated on warmth. Cuddy, Norton and Fiske (2005) found that an elderly retiree described as behaving highly incompetently, and thus confirming the incompetence stereotype, was perceived as higher in warmth then the same retiree depicted as behaving more competently, and thus disconfirming the incompetence stereotype. Hence, if an older worker does not behave in consistency with the low competence group stereotype, warmth perceptions for this person might decrease. Similar effects have been observed for women in professional settings: when women behave competently and thus inconsistently with low competence stereotypes, they are devalued on warmth (Glick and Fiske, 2001). Our findings further suggest that the negative part of the older worker stereotype is more robust than the positive part: if older workers behaviourally disconfirm their negative group stereotype, they decrease their positive stereotype (i.e. they are considered less warm), without enhancing their negative stereotype (i.e. they are still considered incompetent). Therefore, for older workers, demonstrating competence may be costly: it may not only fail to buy due respect but also cost liking.

\section{Limitations and directions for future research}

We chose a controlled, experimental setting, using simulations, to establish the effect of candidate age on selection and its underlying mechanisms. Simulations are artificial but resemble the real world in the sense that they provide evaluators with large amounts of potentially relevant information - a recurrent situation for 
organizational decision makers (Finkelstein and Farrell, 2007). We tried to render the simulation as realistic as possible. Nonetheless, judgements had no real consequences, decreasing the studies' external validity. A field study would allow examining whether differences we observed within the experiments correspond to differences in actual selection situations.

Two of the three studies were conducted with young adults. It is possible that older worker stereotypes differ as a function of evaluator age. However, young and older people's age stereotypes are strikingly similar (e.g. Hummert et al., 1994). Moreover, in our studies, the impact of older worker stereotypes was similar across different samples, further suggesting that older worker stereotypes are comparable across age groups. Nevertheless, evaluators' attitudes toward age and older workers may become increasingly important because, in the light of the current ageing of the population, not only are candidates older but personnel decision makers too. Thus, future research should increasingly consider evaluators' own age and measures of evaluators' attitudes toward age.

This research focused on male workers, to reduce the complexity of the experimental design. It remains an open question to what extent results apply also to female workers because views about older men and women differ. Research suggests that older women are perceived as being higher in warmth than older men (Kite and Smith Wagner, 2002). They are also age-stereotyped at a younger age than men. Hence, future research should explore to what extent age bias at employment affects men and women differently.

\section{Practical implications}

This research indicates that stereotypical beliefs about older workers' low competence underlie age discrimination at hiring. Although not the topic of this research, we would like to point out that this belief is false: age is unrelated to task performance at work ( $\mathrm{Ng}$ and Feldman, 2008). Nevertheless, our study and others suggest that the low competence belief is particularly dominant and robust. Thus, interventions targeting this stereotypical (false) belief in personnel decision makers may be particularly effective in reducing age discrimination. An intervention with this focus should help evaluators realize that the low competence stereotype is (1) false and (2) tends to be consistently applied to older workers, often independently of the competence level of the individual worker, thus increasing evaluators' awareness for the stereotype and its impact. The first goal could be attained by confronting participants with the empirical evidence. It seems important to explain that, despite the fact that certain cognitive functions (those related to fluid intelligence) decline with increasing age, work performance is usually not affected because, for example, people develop effective compensatory strategies (see $\mathrm{Ng}$ and Feldman, 2008). The second goal could be attained by engaging, for example, in interview simulations. During the exercise, evaluators' stereotypical assumptions should be questioned critically (if necessary) to demonstrate their impact and illustrate at which step of the selection process stereotypical low competence beliefs are likely to bias evaluators' judgements. At this point, the role of warmth perceptions could also be discussed. As suggested above, competent older workers may be perceived as less warm. This mechanism could become apparent during the simulation and thus effectively be addressed in training. The aspired overall outcome of an intervention focusing on stereotypes would be that evaluators' better knowledge and increased awareness makes them less apt to rely on stereotypes when making personnel decisions. Nevertheless, stereotypical beliefs are difficult to change. Thus, interventions targeting stereotypes should be accompanied by measures that aim at shaping the selection context, to reduce discrimination (e.g. by implementing structured interviews; e.g. Bragger et al., 2002).

\section{Conclusions}

This research emphasizes the important role of stereotyping for employment discrimination against older workers, focusing on warmth and competence as the two core dimensions in social judgement. Older workers were perceived as less competent but warmer than younger workers. Nevertheless, even if the job primarily required warmth-related qualities, older candidates were discriminated against. Results showed that these discriminatory responses were mediated by inferences related to candidates' competence and 
warmth, providing direct evidence for the mechanism that drives age discrimination and thus filling an important gap in the literature.

Further, this research implies that current demographic changes have not yet paralleled changes in personnel decision making, and that this is due, in part, to stereotyping older workers as incompetent. Excluding older workers based on this false belief is not only unfair but may also deprive organizations of unused potential and increase the risk of personnel shortage. However, organizations that promote bias-free personnel decision making may ultimately have a competitive advantage over those who do not.

\section{References}

Abele, A. and B. Wojcizske (2007). 'Agency and communion from the perspective of self versus others', Journal of Personality and Social Psychology, 93, pp. 751-763.

Bird, C. P. and T. D. Fisher (1986). 'Thirty years later: attitudes toward the employment of older workers', Journal of Applied Psychology, 71, pp. 515-517.

Bragger, J. D., E. Kutcher, J. Morgan and P. Firth (2002). 'The effects of the structured interview on reducing bias against pregnant job applicants', Sex Roles, 46, pp. 215-226.

Chiu, W. C. K., A. Chan, E. Snape and R. Redman (2001). 'Age stereotypes and discriminatory attitudes toward older workers: an East-West comparison', Human Relations, 54, pp. 629-661.

Craft, J. A., S. I. Doctors, Y. M. Shkop and T. J. Benecki (1979). 'Simulated management perceptions, hiring decisions, and age', Aging and Work, 3, pp. 95-102.

Cuddy, A. J. C. and S. T. Fiske (2002). 'Doddering but dear: process, content, and function in stereotyping of older persons'. In T. D. Nelson (ed.), Ageism: Stereotyping and Prejudice Against Older Persons, pp. 3-26. Cambridge, MA: MIT Press.

Cuddy, A. J. C., S. T. Fiske and P. Glick (2008). 'Warmth and competence as universal dimensions of social perception: the stereotype content model and the BIAS map', Advances in Experimental Social Psychology, 40, pp. 61-149.

Cuddy, A. J. C., M. I. Norton and S. T. Fiske (2005). 'This old stereotype: the pervasiveness and persistence of the elderly stereotype', Journal of Social Issues, 61, pp. 267-285.

Cuddy, A. J. C., S. T. Fiske, V. S. Y. Kwan, P. Glick, S. Demoulin, J.-P. Leyens, M. H. Bond, J.-C. Croizet, N. Ellemers, E. Sleebos, T. T. Htun, H.-J. Kim, G. Maio, J. Perry, K. Petkova, V. Todorov, R. Rodriguez-Bailon, E. Morales, M. Moya, M. Palacios, V. Smith, R. Perez, J. Vala and R. Ziegler. (2009). 'Stereotype content across cultures: towards universal similarities and some differences', British Journal of Social Psychology, 48, pp. 1-33.

Diekman, A. B. and L. Hirnisey (2007). 'The effect of context on the silver ceiling: a role congruity perspective on prejudiced responses', Personality and Social Psychology Bulletin, 33, pp. 1353-1366.
Eagly, A. H. (1987). Sex Differences in Social Behavior: A Social-role Interpretation. Hillsdale, NJ: Lawrence Erlbaum. Eagly, A. H. and A. B. Diekman (2005). 'What is the problem? Prejudice as an attitude-in-context'. In J. F. Dovidio, P. Glick and L. A. Rudman (eds), On the Nature of Prejudice: Fifty Years after Allport, pp. 19-35. Malden, MA: Blackwell.

Eagly, A. H. and S. J. Karau (2002). 'Role congruity theory of prejudice toward female leaders', Psychological Review, 109, pp. 573-598.

Eagly, A. H. and A. Mladinic (1989). 'Gender stereotypes and attitudes toward women and men', Personality and Social Psychology Bulletin, 15, pp. 543-558.

Eagly, A. H. and S. Sczesny (2008). 'Stereotypes about women, men, and leaders: have times changed?' In M. Barreto, M. Ryan and M. Schmitt (eds), The Glass Ceiling in the 21st Century: Understanding Barriers to Gender Equality, pp. 2147. Washington, DC: American Psychological Association.

European Commission (2009). '16\% of Europeans report experiencing discrimination. Ageism is growing problem - or so most Europeans think'. Retrieved 11 November 2009 from http://www.ec.europa.eu/news/employment/091110_en.html.

Finkelstein, L. M. and S. K. Farrell (2007). 'An expanded view of age bias in the workplace'. In K. Shultz and G. Adams (eds), Aging and Work in the 21st Century, pp. 73-108. Hillsdale, NJ: Lawrence Erlbaum.

Finkelstein, L. M., M. J. Burke and N. S. Raju (1995). 'Age discrimination in simulated employment contexts: an integrative analysis', Journal of Applied Psychology, 80, pp. 652-663.

Finkelstein, L. M., K. Higgins and M. Clancy (2000). 'Justifications for ratings of old and young job applicants: an exploratory content analysis', Experimental Aging Research, 26, pp. 263-288.

Fiske, S. T., A. J. C. Cuddy and P. Glick (2007). 'Universal dimensions of social cognition: warmth and competence', Trends in Cognitive Sciences, 11, pp. 77-83.

Fiske, S. T., A. J. C. Cuddy, P. Glick and J. Xu (2002). 'A model of (often mixed) stereotype content: competence and warmth respectively follow from perceived status and competition', Journal of Personality and Social Psychology, 82, pp. 878-902.

Glick, P. and S. T. Fiske (2001). 'Ambivalent stereotypes as legitimizing ideologies: differentiating paternalistic and envious prejudice'. In J. Jost and $\mathrm{B}$. Major (eds), The Psychology of Legitimacy, pp. 278-306. Cambridge: Cambridge University Press.

Gordon, R. A. and R. D. Arvey (2004). 'Age bias in laboratory and field settings: a meta-analytic investigation', Journal of Applied Social Psychology, 34, pp. 1-27.

Hassell, B. L. and P. L. Perrewe (1995). 'An examination of beliefs about older workers: do stereotypes still exist?', Journal of Organizational Behavior, 16, pp. 457-468.

Heilman, M. E. (1983). 'Sex bias in work settings: the lack of fit model', Research in Organizational Behavior, 5, pp. 269-298.

Hummert, M. L., T. A. Garstka, J. L. Shaner and S. Strahm (1994). 'Stereotypes of the elderly held by young, middleaged, and elderly adults', Journal of Gerontology: Psychological Sciences, 49, pp. 240-249.

Judd, C. M., D. A. Kenny and G. H. McClelland (2001). 'Estimating and testing mediation in within-subject designs', Psychological Methods, 6, pp. 115-134.

Kelly Services (2006). 'Discrimination emerging in new forms in the global jobs market'. Retrieved 10 October 2008 from 
Business and Human Rights Resource Center website: http:// www.reports-and-materials.org/Kelly-discrimination-survey2006.pdf.

Kite, M. E. and L. Smith Wagner (2002). 'Attitudes toward older adults'. In T. D. Nelson (ed.), Ageism: Stereotyping and Prejudice Against Older Persons, pp. 129-162. Cambridge, MA: MIT Press.

Kluge, A. and F. Krings (2008). 'Attitudes toward older workers and human resource practices', Swiss Journal of Psychology, 67, pp. 61-64.

Krings, F. and J. Olivares (2007). 'At the doorstep to employment: discrimination against immigrants as a function of applicant ethnicity, job type, and raters' prejudice', International Journal of Psychology, 42, pp. 406-417.

Lawrence, B. S. (1988). 'New wrinkles in the theory of age: demography, norms, and performance ratings', Academy of Management Journal, 31, pp. 309-337.

Lyon, P. and D. Pollard (1997). 'Perceptions of the older employee: is anything really changing?', Personnel Review, 26, pp. 245-257.

McGregor, J. and L. Gray (2002). 'Stereotypes and older workers: the New Zealand experience', Social Policy Journal of New Zealand, 18, pp. 163-177.

Ng, T. W. H. and M. C. Feldman (2008). 'The relationship of age to 10 dimensions of job performance', Journal of Applied Psychology, 93, pp. 392-423.

Perry, E. L. (1994). 'A prototype matching approach to understanding the role of applicant gender and age in the evaluation of job applicants', Journal of Applied Social Psychology, 24, pp. 1433-1473.

Perry, E. L., C. T. Kulik and A. C. Bourhis (1996). 'Moderating effects of personal and contextual factors in age discrimination', Journal of Applied Psychology, 81, pp. 628647.
Phalet, K. and E. Poppe (1997). 'Competence and morality dimensions of national and ethnic stereotypes: a study in six eastern-European countries', European Journal of Social Psychology, 27, pp. 703-723.

Posthuma, R. A. and M. A. Campion (2009). 'Age stereotypes in the workplace: common stereotypes, moderators, and future research directions', Journal of Management, 35, pp. $158-188$.

Redman, T. and E. Snape (2002). 'Ageism in teaching: stereotypical beliefs and discriminatory attitudes towards the over 50s', Work, Employment and Society, 16, pp. 353-369.

Redman,. T. and E. Snape (2006). 'The consequences of perceived age discrimination amongst police officers: is social support a buffer?', British Journal of Management, 17, pp. $167-175$.

Rosen, B. and T. H. Jerdee (1976). 'The influence of age stereotypes on managerial decisions', Journal of Applied Psychology, 61, pp. 428-432.

Rupp, D. E., S. J. Vodanovich and M. Credé (2006). 'Age bias in the workplace: the impact of ageism and causal attributions', Journal of Applied Social Psychology, 36, pp. 13371364.

Shore, L. M. and C. B. Goldberg (2005). 'Age discrimination in the workplace'. In R. L. Dipboye and A. Colella (eds), Discrimination at Work: The Psychological and Organizational Bases, pp. 203-226. Mahwah, NJ: Lawrence Erlbaum.

Suitner, C. and A. Maass (2008). 'The role of valence in the perception of agency and communion', European Journal of Social Psychology, 38, pp. 1073-1082.

Warr, P. and J. Pennington (1993). 'Views about age discrimination and older workers'. In P. Taylor, A. Walker, B. Casey, H. Metcalf, J. Lakey, P. Warr, and J. Pennington (eds), Age and Employment: Policies, Attitudes and Practices, pp. 75-106. London: Institute of Personnel Management.

Franciska Krings received her PhD in psychology at the University of Bern. She is currently an assistant professor at the Department of Organizational Behaviour of the University of Lausanne. Her main research interests are concerned with antecedents and consequences of stereotyping and prejudice and with age from a life-span perspective. Her work has appeared in the Journal of Applied Psychology, Journal of Applied Social Psychology, Journal of Business Ethics and Journal of Research in Personality.

Sabine Sczesny received her $\mathrm{PhD}$ in psychology at the University of Kiel, Germany. She is a professor of social psychology at the University of Bern, Switzerland. In her research she focuses on basic and applied aspects of stereotyping and social discrimination. Her research has been published in the European Journal of Social Psychology, Personality and Social Psychology Bulletin, Social Cognition and Work and Stress.

Annette Kluge is a professor for business and organizational psychology at the University of Duisburg-Essen. She received her $\mathrm{PhD}$ in trainings science and ergonomics at the University of Kassel. Her main research interests are training in high reliability organizations, learning in organizations and organizational learning in complex environments. Her work has appeared in the International Journal of Management Review, Cognition, Work and Technology, Human Factors, Ergonomics and Computers in Human Behavior. 